\title{
Sobre un tópico equivocado (las representaciones de las comedias de Plauto y Terencio en España a finales del siglo xv) y Celestina ${ }^{1}$
}

\author{
Devid Paolini \\ The City College of New York
}

De la estrecha relación entre la comedia romana y la Tragicomedia de Calisto y Melibea ha tratado ya detenidamente Lida de Malkiel en su La originalidad artística de "La Celestina». Allí la estudiosa defendía no solo la dependencia de la obra maestra española del corpus de Plauto y, sobre todo, Terencio, ${ }^{2}$ sino que enmarcaba la Tragicomedia en el género dramático. A partir de estas dos premisas (la comedia romana como modelo y $\mathrm{Ce}$ lestina como drama) se desarrolla el presente trabajo, en el que se hablará de la posible representación de los textos de los dos dramaturgos latinos en centros universitarios y ciudades españolas en las últimas décadas del siglo XV. Sin embargo, antes de analizar la situación del teatro clásico en España, será oportuno hablar brevemente de la puesta en escena de comedias y tragedias clásicas en Italia, por haber sido la península el centro de irradiación del teatro renacentista.

La primera noticia de una representación de una comedia clásica en la península italiana viene de Florencia, ${ }^{3}$ donde, desde ya 1476, el maestro

1.- Una primera versión del presente trabajo, aquí ampliada, mejorada y corregida, fue leída en Montreal a finales de mayo de 2010 durante el congreso anual de la Asociación Canadiense de Hispanistas. La presente investigación ha sido posible gracias a una beca del PSC-CUNY, concedida conjuntamente por The Professional Staff Congress y The City University of New York (Support for this project was provided by a PSC-CUNY Award, jointly funded by The Professional Staff Congress and The City University of New York).

2.- «Todo examen de La Celestina confirma esta conclusión: la comedia romana y en especial la de Terencio ha sido el modelo - directo e indirecto- para un gran número de resortes técnicos, tales como ciertos tipos de acotación, diálogo, monólogo, aparte, ironía» (1970: 30).

3.- Tratan de la puesta en escena de comedias clásicas en Florencia, Del Lungo (1876), Pintor (1906a) y Doglio (1971). 
de escuela Giorgio Antonio Vespucci, amigo de Poliziano y Ficino, y tío del futuro navegador Américo, había pedido a sus discípulos que pusieran en escena el Andria de Terencio. ${ }^{4}$ El éxito de la recitación y su reconocido valor pedagógico atrajo la atención de otros maestros y profesores como Luca d'Antonio Bernardi de San Gimignano y Paolo Comparini de Prato. Al primero, que enseñó gramática en el Estudio florentino desde 1485 hasta 1498, se deben representaciones tanto de los Diálogos de Luciano como de dramas que él mismo compuso y de una comedia de Plauto cuyo título no nos ha llegado (Ventrone 1993: 25 y n. 33); el segundo escenificó con sus estudiantes, el 12 de mayo de 1488, los Menaechmi de Plauto con un prólogo de Angelo Poliziano. ${ }^{5}$ Este último fue, sin duda alguna, uno de los humanistas más eruditos que empujó a la recuperación del teatro clásico. En el curso sobre el Andria de Terencio que impartió entre 1484 y 1485, además de analizar detenidamente el texto, se ocupó por primera vez de reconstruir la historia de la comedia desde su origen griego hasta la época de los dos dramaturgos romanos. ${ }^{6}$

El interés de los humanistas florentinos no estaba limitado a la recuperación del teatro clásico romano. De hecho se conservan testimonios que nos informan de cómo, en la última década del Quattrocento, se representaron en Florencia también dramas griegos, uno de los cuales por lo menos en lengua original: en un epigrama griego de Poliziano se lee un elogio entusiasta de la actuación de Alessandra Scala, hija del canciller de la República florentina Bartolomeo Scala, quien recitó el papel de Electra en la tragedia homónima de Sófocles. ${ }^{7}$ La representación tuvo lugar alrededor de 1493, como nos indica el mismo Poliziano en una carta a Cassandra Fedele. ${ }^{8}$

4.- De la representación, que tuvo lugar durante el carnaval de dicho año, nos habla Pietro Cennini en una carta a Alamanno Rinuccini, este último embajador de Lorenzo el Magnífico en Roma. Recuerda todo el episodio y señala la bibliografía fundamental Ventrone (1993: 23 y n. 26).

5.- Para el polémico prólogo de Poliziano, escrito en defensa de Lorenzo el Magnífico contra los ataques de los eclesiásticos que criticaban las representaciones de comedias clásicas, véanse Bombieri (1985), Bausi (1991), (Ventrone 1993: 27, 35-6) y Martelli (1993). Del interés del Magnífico por las comedias clásicas es testigo también un soneto escrito por Feo Belcari hacia 1480, en el que Plauto y Terencio se presentan como fuentes de la elocuencia del ilustre miembro de la familia Medici: «Nel tuo intelletto el bel Terenzio e Plauto / Versan le muse lor, como Nettunno / Le grand'acque del verno e dell'autunno, / Per farti sempre di eloquenzia lauto...» (Belcari 1833: 173; apud Ventrone 1993: 34, n. 56).

6.- Lattanzi Roselli (1973) ha transcrito y preparado la edición crítica de los apuntes del curso de Poliziano que se han conservado. Véase, además, Ventrone (1992; 1993: 36-8, 171-7).

7.- «Cuando la joven Alessandra representó a Electra... todos nos quedamos estupefactos por la facilidad con la que hablaba la lengua ática sin caer en error, aunque era italiana de estirpe, por cómo emitía la voz bien imitada y natural, y por cómo observaba la buena regla del arte escénico» (la traducción, que se basa en la italiana al cuidado de Ardizzoni 1951: 56, es nuestra).

8.- La epístola puede leerse en Pesenti (1915: 299-301), a quien se debe también su datación. Sobre la humanista veneciana, véase Robin (2000). Todo el episodio se recuerda en Ventrone (1993: 28-9 y notas). 
Otra referencia a posibles representaciones en griego se encuentra en el prefacio de la Ionià escrita por el humanista heleno Aristóbulo Apostoli. ${ }^{9}$ En la dedicatoria a León x (Giovanni de' Medici, hijo del Magnífico), se habla de una representación del Pluto de Aristófanes. Este es el pasaje:

Le debo esto al muy docto Giano Lascaris, el más ilustre de la estirpe de los griegos, quien, con muchos esfuerzos e ingentes gastos del muy noble y muy ilustre padre de Vuestra Santidad, los libros de aquellos antiguos y felices hombres... llevó a salvo a Florencia, donde yo, copiando una parte para el magnífico y noble Piero, hermano de Vuestra Santidad... otra parte consultándola según mis fuerzas, recogíy reuní los pasajes mejores, como hacen las abejas con las flores más perfumadas y bellas. Me atrajo también a mí en aquel entonces a Florencia, a través del muy sabio Lascaris, Lorenzo [el Magnífico], el gran iluminado filo-helénico, excelsa cima y gloria de la nobleza florentina, y allí conocí también a Tu Santidad. ¿Qué tiempo era, qué tiempo remoto era aquel, en que también una escena, como en una nueva Atenas, hiciste aparejar espléndidamente en tu suntuosa morada para el "Pluto» de Aristófanes? Esta pequeña obra, Santísimo Señor, por fin llevada a cabo te la ofrezco pues, muy sabio pontífice, a cambio de la benevolencia que el muy magnífico y muy noble consanguíneo tuyo Piero tuvo hacía mí y por el fervor hacia el estudio del griego que Tu Santidad ha heredado de sus predecesores y conserva. ${ }^{10}$ (El subrayado es nuestro).

La presencia de Aristóbulo Apostoli en Florencia puede datarse con cierta seguridad hacia mediados de 1492. Considerando el hecho de que los Medici fueron expulsados de la ciudad en 1494 y no regresaron hasta 1512, pocos meses antes de la elección de Giovanni de' Medici a la sede pontificia, la primera fecha puede tomarse como terminus post quem y el año 1494 como término ante quem de dicha representación. ${ }^{11}$

9.- Esta información nos la comunicó personalmente nuestro querido amigo Stefano Pagliaroli, quien, amablemente, nos pasó una copia de su artículo que estaba en prensa y se publicó luego en 2004. A él va nuestro sincero agradecimiento.

10.- La traducción al español es nuestra y se basa en la que hizo el autor del artículo del griego al italiano (el texto original se encuentra en Legrand 1885, II: 340-1; el pasaje que se ha traducido en Pagliaroli 2004: 235-6).

11.- Staüble (1968: 16) afirma que el Pluto se puso en escena en griego en Florencia a finales del siglo xv y reenvía en nota a la voz Aristófanes, al cuidado de Gennaro Perrotta, en la Enciclopedia dello Spettacolo (1954-1962, vol. 1: 871). La única información que Perrotta da, sin añadir bibliografía, es la siguiente: «Antes de la editio princeps (1498), los humanistas Geronimo [sic por Guarino] Veronese, Giovanni Aurispa, Gaspare da Verona, Lionoro de' Leonori, Francesco Barbaro, Lorenzo Valla, Bessarione y Poliziano poseyeron códices de Aristófanes o 
En Roma ${ }^{12}$ el intento de recuperar el teatro clásico está vinculado a la asidua actividad de Pomponio Leto (1428-1498), el humanista que más promovió la restauración de la cultura de la antigüedad romana. Llegado a la Urbe en torno a mediados del siglo, el papa Pablo in le asignó la cátedra de elocuencia en el Estudio romano; fue por su iniciativa que empezó a formarse la Academia romana (conocida también como Academia pomponiana dada la importancia de la aportación de Pomponio), en la que diferentes estudiosos del mundo clásico no solo asumieron nombres latinizantes, con los que se les conoce, sino que fechaban sus escritos con el famoso epígrafe liviano $A b$ urbe condita. En sus reuniones debatían temas y problemas de filosofía, arte, filología, y cada año el 21 de abril, según la tradición clásica, conmemoraban la fundación de Roma (Rossi 1973: 303-8).

En 1468 Pomponio Leto fue encarcelado junto con Bartolomeo Sacchi, más conocido como Platina, y con otros socios de la academia, bajo la acusación de preparar una conjura contra el papa para restaurar la república romana. Esto causó la dispersión de la Academia, que solo con la muerte de Pablo II (1471) y la elección de su sucesor, Sixto Iv, pudo reanudar sus actividades. Al nuevo pontífice, mecenas de artistas y letrados, se deben el embellecimiento de los palacios Vaticanos y de San Pedro, la construcción de la capilla que se denominó luego Sixtina, y la ampliación y apertura al público de la Biblioteca Vaticana, que confió, en 1475, a la dirección de Platina.

La Academia romana recobró vigor y en 1483 el emperador Federico III le confirió la facultad de nombrar doctores y coronar poetas. Precisamente a Pomponio Leto se le debe la restauración del teatro clásico en Roma, gracias también al mecenazgo de los nietos de Sixto Iv, Girolamo y los cardenales Pietro y Raffaele Riario. En efecto, en abril de 1486 los pomponianos representaron en el Capitolio el Epidicus de Plauto mientras que Gian Sulpizio de Veroli, amigo de Leto, organizó en Campo de' Fiori la recitación del Hypolitus de Séneca. ${ }^{13}$ En esta última se distinguió entre los actores el joven Tommaso Inghirami, a quien, desde aquel entonces, se le apodó con el nombre de Fedra por su excelente interpretación de la protagonista femenina de la tragedia senequiana. ${ }^{14}$ En los años siguien-

hicieron extractos de sus obras. Leonardo Bruni tradujo al latín el primer acto del Pluto, porque quería que se conocieran el carácter de la comedia griega y sus diferencias con las comedias de Plauto y Terencio; y así fue el iniciador del teatro humanístico. Por cierto que, por influjo de Bruni, en la segunda mitad del Quattrocento se representó en Florencia el Pluto en el texto griego» (la traducción al español es nuestra).

12.-Para el teatro y los espectáculos en Roma, vénase Pintor (1906b) y la ingente documentación que ha recogido Cruciani (1983). En cuanto a la academia pomponiana, de la que se hablará enseguida, sigue siendo fundamental el estudio de Zabughin (1909-1912), que habrá de ponerse al día con Neiiendam (1969).

13.- Hay una evidente errata en Rossi (1973: 504-5), que sitúa estos dos espectáculos en 1468. Véase, a propósito de esto, Cruciani (1983: 184-8).

14.- Véanse Cruciani (1980; 1983: 39-44) y Pieri (1989: 61). 
tes tenemos constancia de la puesta en escena del Amphitruo en 1492, la Aulularia en 1497, la Mostellaria en 1499, los Menaechmi en 1501 (para festejar las bodas de Lucrecia Borgia y Alfonso d'Este), y unas cuantas comedias durante el carnaval de 1503 (Stäuble 1968: 201). Una alusión indirecta a una posible representación en griego en Roma viene del Diario de Jacopo Gherardi y, en particular, de la descripción de una cena ofrecida por el embajador veneciano Francesco Diedo: durante el banquete hubo personas "qui graece recitarunt» $\mathrm{y}$ "qui comoedias actitarunt», según los "veterum mores et acta» (Cruciani 1983: 186), único indicio de este tipo de espectáculo en la Roma pontifical.

El centro más importante por la representación de comedias romanas fue, de todos modos, Ferrara, sobre todo en los últimos quince años del Quattrocento, cuando la ciudad se encontraba bajo el mecenazgo de Ercole I (Cruciani, Falletti y Ruffini 1994). Hay que señalar una particularidad que iba a tener consecuencias muy importantes: las obras de Plauto y Terencio ya no se representaban en lengua original sino traducidas a la vernácula. Esto indica una finalidad totalmente diferente con respecto a las primeras comedias clásicas que se habían puesto en escena en Florencia: si allí el objetivo de los maestros de escuela era principalmente didáctico, el uso de la lengua vulgar en Ferrara demuestra claramente cómo en la corte de los Este se había recuperado in toto el concepto de espectáculo teatral como diversión para un público más amplio compuesto por sectores de la sociedad que no entendían latín. ${ }^{15}$ En 1479, para el duque Ercole, Battista Guarino había traducido la Aulularia y el Curculio; unos años más tarde también los Menaechmi; Girolamo Berardi volvió en lengua vulgar la Casina y la Mostellaria; y Paride Ceserani de nuevo la Aulularia; todas comedias de Plauto. El 25 de enero de 1486, poco meses antes de las representaciones romanas, tuvo lugar en Ferrara la primera recitación de una comedia de Plauto de que se tiene noticia: los Menaechmi, en traducción, naturalmente. ${ }^{16} \mathrm{Al}$ año siguiente le tocó el turno al Amphitruo, mientras que en 1491, con ocasión del matrimonio de Alfonso d'Este con Anna Sforza, además de las dos comedias plautinas ahora recordadas se representó el Andria de Terencio. En mayo de 1493, durante la visita de Ludovico el Moro a la ciudad de Ferrara, se recitaron de nuevo los $\mathrm{Me}$ naechmi; para el carnaval de 1499 el terenciano Eunucus y las dos comedias plautinas Trinumnus y Poenulus; en 1500 la Asinaria; en 1501 los Captivi, el Mercator, la Asinaria y el Eunuchus. En 1502, para celebrar las nuevas bodas de Alfonso con Lucrecia Borgia, se pusieron en escena hasta cinco come-

15.- Acerca de la traducción de las comedias de Plauto y Terencio a finales del Quattrocento y a lo largo del siglo siguiente, véanse De Amicis (1897), Orlando (1940), Rositi (1968), Coppo (1968), Stefani (1979), Uberti (1985) y Ruffini (1987).

16.- Estudio y texto pueden leerse en Tissoni Benvenuti y Mussini Sacchi (1983: 77 y sigs.). Véase, además, Ruffini (1987). Sobre la fortuna de esta comedia de Plauto en particular, y su representación tanto en latín como en traducción, véase Uberti (1985: 7-12). 
dias plautinas: la Casina, el Epidicus, las Bacchides, el Miles gloriosus y la Asinaria. En 1503 fue el turno de la Aulularia, la Mostellaria, los Menaechmi y el Eunucus (Stäuble 1968: 200; Coppo 1968; y Rossi 1973: 505-6), etc.

La recitación de comedias clásicas traducidas en lengua vernácula no fue un fenómeno exclusivo de Ferrara: en pocos años otras cortes y ciudades italianas siguieron el ejemplo de los Este. En Bolonia se escenificaron las comedias Amphitruo (1487) y Menaechmi (1491); esta última también en Cesena en 1492; en Mantua los Gonzaga asistieron a la representación de los Captivi (1496), del Poenolus y de la terenciana Adelphoe (1501), y de los Menaechmi, el Trinummus y el Pseudolus (1502); y desde 1507 se instaló en Venecia Francesco Nobili, apodado "Cherea ${ }^{17}$ —por su interpretación del homónimo personaje de la comedia terenciana Eunuchus- que impulsó, en las siguientes dos décadas, la puesta en escena de las comedias de Plauto y Terencio en lengua vulgar (Pieri 1989: 64; Padoan 1996: 11).

En Nápoles, la única noticia indirecta de la recitación de una comedia plautina nos viene del prólogo del drama humanístico Comedia sine titulo de Girolamo Morlini (Stäuble 1968: 214).

Por último nos queda por considerar Milán, donde, según las informaciones que nos han llegado, parece que no arraigó la costumbre de poner en escena las obras de Plauto y Terencio. De hecho, las únicas representaciones de comedias romanas que se organizaron en el ducado se debieron a los ferrareses. ${ }^{18}$ Como ya se ha dicho, el 24 de mayo de 1493, en ocasión de la estancia en Ferrara de los señores de Milán, Ludovico el Moro y su esposa Beatrice d'Este, se habían recitado los Menaechmi de Plauto (Coppo 1968: 37). Ludovico se había quedado tan entusiasmado que deseó ver de nuevo el espectáculo en su ciudad (32). Por eso, cuando Ercole d'Este se fue a su vez a visitar a su yerno, en agosto del mismo año, llevó consigo «le genti, che recitarono il Menechino», según la crónica de Paolo de Legnano (apud Arata 1934: 202, n. 1). ${ }^{19}$ Testimonio de esta representación nos viene también de una carta de Isabella d'Este a su marido, fechada el 28 de julio de 1493, donde le comunicaba la intención del duque de Ferrara, su padre, de poner en escena dicha obra:

17.- Sobre "Cherea» y su importante contribución al espectáculo en Venecia, véanse Padoan (1982: 35-46), Guarino (1987; 1995), y la voz «De Nobili, Francesco» en el Dizionario Biografico degli Italiani.

18.- Que en Milán no se representaran comedias clásicas no quiere decir en absoluto que no tuviera una buena tradición dramática. Será suficiente recordar la representación alegórica de Bernardo Bellincioni titulada Fiesta del Paraíso (1490), que tuvo como escenario el Castillo Sforzesco y como colaborador al mismo Leonardo da Vinci (Sanesi 1911, I: 196-7).

19.- La noticia de esta representación milanesa parece haber caído en olvido dado que no se alude a ella ni en Stäuble (1968: 201), ni en Rossi (1973: 511), etc. Nuestra información ha venido de Uberti (1985: 8), que a su vez reenvía al estudio de Arata (1934), que se ha consultado y citado hace poco. 
Lo ill.mo Sig. mio patre prega V.S. che la voglia prestarli dui turbanti et dui habiti turcheschi da vestire due persone, quali voria per portar seco a Milano per la comedia de Menechino ch'el vole fare per satisfactione del S. Ludovico. (Luzio y Renier 1890: 379)

Y todavía en agosto de 1493, el señor de Milán se fue a Pavía, donde el duque de Ferrara había enviado a un grupo de jóvenes, entre ellos el joven Ludovico Ariosto, para representar los días 27, 28 y 29 tres comedias plautinas: los Captivi, el Mercator y el Poenulus (ib.; Rossi 1973: 511).

Las actividades teatrales que se acaban de enumerar solo se refieren a la representación de comedias y tragedias clásicas. Se dejan de mencionar, porque no están directamente relacionadas con el tema de esta investigación, las numerosas recitaciones sagradas (sobre todo en Florencia), ${ }^{20}$ los festejos y espectáculos organizados en ocasión de la elección de un nuevo papa o de un doge en Venecia, la visita de personajes importantes, las entradas reales, la recitación de dramas mitológicos y alegóricos, églogas, farsas, comedias humanísticas, etc. ${ }^{21}$

Todo lo dicho demuestra claramente las múltiples manifestaciones teatrales y la tan arraigada cultura del espectáculo y de la puesta en escena de comedias y tragedias clásicas en la península italiana a finales del siglo XV.

En cuanto a España, ¿qué evidencia nos ha llegado de representaciones teatrales de dramas clásicos? No entra en nuestros objetivos tratar, ahora, de la cuestión de si en España hubo o no teatro, materia que dejamos para otra ocasión. Lo que sí nos interesa subrayar es cómo se ha creado, a nuestro entender, un lugar común que ha llevado a algunos estudiosos a afirmar que a finales del siglo se representaban en Castilla las comedias de Plauto y Terencio. Probablemente estas aseveraciones se basan en algunas ideas expuestas por Bonilla y San Martín que luego fueron repetidas y ampliadas por García Soriano y Casas Homs.

Bonilla y San Martín publicó, en 1925, un estudio sobre el teatro universitario durante el renacimiento español y sobre Juan Pérez Petreyo (1512-1545), humanista toledano que enseñó retórica en la universidad de Alcalá de Henares y autor de diferentes comedias humanísticas. Tras afirmar que durante la Edad Media se conocían en España las comedias de Plauto y Terencio y las tragedias de Séneca, y hacer referencia a unas comedias humanísticas que, posiblemente, circularon en Castilla, el estudioso recuerda el título LXI de los Estatutos de la Universidad de Salamanca de 1538, donde se indicaba la necesidad, para cada colegio, de repre-

20.- Véase para Florencia a Molinari (1961), el apéndice de Trexler (1980) y Ventrone (1993: 38-53 y passim; 2008).

21.- Además de los estudios que ya se han señalado, véanse Zorzi (1977), Cruciani y Seragnoli (1987), Guarino (1988), Villoresi (1994) y Padoan (1996). 
sentar una comedia o tragedia clásica. ${ }^{22}$ A continuación añade un pasaje que, creemos, es el que ha dado inicio a toda una serie de malentendidos que persisten hoy en día:

Probablemente, la costumbre de las representaciones no se inauguró en 1538, sino que databa de la Edad Media. Así, en la Universidad de París, según du Boulay, era eso "vetustissima consuetudo»; y, en Inglaterra, sabido es que la creación de la fiesta del Corpus Christi, en 1311, contribuyó poderosamente al desarrollo de las miracle-plays. (1925: 145; el subrayado es nuestro).

Todos los estudios posteriores, como veremos, se refieren a y se basan en esta aseveración.

Poco antes de la mitad del siglo pasado García Soriano en su estudio sobre los orígenes del teatro español afirmó (apoyándose en Bonilla y San Martín y sin aportar documentación adicional) que, si en Francia hubo representaciones teatrales desde los primeros años de la fundación de la Universidad de París, entonces lo mismo o algo parecido tuvo que haber pasado en la Universidad de Salamanca. Esto es lo que escribe:

Ya en la Edad Media las Universidades debieron de celebrar representaciones dramáticas, en solemnidades y fiestas, como diversión y ejercicio literario a la vez. Escribe du Boulay que en la de París era «vetustissima consuetudo». Igual práctica existiría en las Universidades españolas. Si no hay pruebas documentales, anteriores al siglo XVI, que lo confirmen, de la tradición se infiere claramente. (1945: 3)

Por su parte también Casas Homs contribuyó a esta creencia generalizada. En su edición de la comedia humanística Poliodorus, que descubrió en 1953 en la Biblioteca Colombina de Sevilla, en un primer momento habló de los puntos de contacto entre esta y Celestina, y luego concluyó su análisis con la siguiente aseveración:

tanto las razones del Maestro [Menéndez Pelayo] como las que nosotros hayamos podido añadir prueban o dejan adivinar la creación en España de un ambiente dra-

22.- «[De] cada colegio, cada año se representará una comedia de Plauto o Terencio, o tragicomedia, la primera el primero domingo desde las octavas de Corpus Christi, y las otras en los domingos siguientes: $y$ al Regente que mejor hiciere y representare las dichas comedias o tragedias, se le den seis ducados del arca del Estudio, y sean jueces para dar este premio el Retor y Maestrescuela» (Esperabé Arteaga 1914-1917, I: 203). Estos estatutos de 1538 parecen remontarse por lo menos a 1529 cuando era rector de la Universidad el humanista Fernán Pérez de Oliva. Se tratará posteriormente más detenidamente de la cuestión. 
mático estudiantil, paralelo al que un siglo antes se había iniciado en Italia con la obra de P. P. Vergerio. (1953: 164)

En realidad durante la época de Vergerio, es decir, alrededor de las últimas décadas del siglo XIV, en Italia no hubo ningún teatro universitario. Con la excepción de unas pocas farsas, generalmente goliárdicas, que se representaron en los círculos universitarios de Pavía y Padua, y sin considerar la aislada experiencia de Frulovisi en Venecia, todo esto de la tercera década del siglo XV, no se puede hablar de «ambiente dramático estudiantil» en la península italiana antes del último cuarto del Quattrocento, con los maestros florentinos recordados arriba, los pomponiani en Roma y los varios humanistas de la corte Estense de Ferrara (Di Camillo 2005: 70-3).

Estas fueron las semillas que, a nuestro juicio, dieron lugar a este malentendido bastante difundido y repetido que ha llegado hasta nuestros días. Se citarán, a título informativo, solo unos pocos ejemplos.

Gilman, en su The Spain of Fernando de Rojas, en referencia a la Universidad de Salamanca escribe:

In addition to classroom study of Terence, performance or at least dramatic reading of the dialogue of classical and humanistic works seems to have been a regular custom. Although there are no specific records of such events in Rojas' time, the 1501 publication in Salamanca of Alberti's Philodoxus would indicate that the 1538 regulation to the effect that certain Sundays be set apart for the representation of a "Comedia de Plauto o Terencio o Tragicomedia» was based on earlier tradition. (1972: 312)

Las palabras de Gilman necesitan ser matizadas y puestas en su justo contexto. Si por un lado es verdad que en 1501 se publicó en la ciudad salmantina el Philodoxus de Leon Battista Alberti, por otro, en el prólogo que acompaña al texto en cuestión, escrito por el bachiller Quirós, se nos dice que dicha comedia humanística era totalmente desconocida en la época en la Universidad de Salamanca. ${ }^{23} \mathrm{Ni}$ hay alusión alguna a que se recitara o se representara. Por lo tanto no creemos que de la publicación del Philodoxus se pueda inferir que a finales del siglo xv se representaban en Salamanca las obras de Plauto y Terencio, tal y como requerían los estatutos del ateneo salmantino de 1538.

En tiempos más recientes, durante el I Simposio sobre humanismo y pervivencia del mundo clásico que se celebró en Alcañiz en 1990, Picón García presentó, en nombre del grupo del que forma parte, un proyecto de in-

23.- La carta prólogo puede leerse en Menéndez Pelayo (1910: 71-2, n. 2). Allí Quirós afirma que había decidido promover la impresión de la comedia para que no se quedara omnibus incognitum un texto escrito summa cum elegantia ac venustate. 
vestigación sobre el teatro humanístico en España. Después de unas pocas palabras introductorias, el estudioso declaró:

Sobre la existencia de representaciones teatrales en las Universidades españolas desde la fundación de la primera de ellas en Palencia no debe haber duda alguna, puesto que eso mismo ocurría en las Universidades extranjeras en la Edad Media, como está perfectamente documentado en alguna de ellas. (1993: 822)

Y reenvía en nota a Bonilla y San Martín y Casas Homs.

Hablando del teatro estudiantil español del Renacimiento, Alonso Asenjo centró su atención en aquellas obras dramáticas que se representaron con el objetivo didáctico de ayudar a los estudiantes en el aprendizaje del latín y de la retórica. Y escribe:

Esta actividad teatral se desarrolla sobre todo a partir de la última década del siglo XV y su punto de arranque es el estudio y consiguiente representación de las obras de Plauto y Terencio, y también de Séneca y de los trágicos griegos, especialmente de Eurípides... La costumbre de las representaciones plautinas y terencianas se prolongará en los centros de estudios a lo largo de todo el siglo XVI. (1998: 164)

A estas referencias específicas habría que añadir también unas cuantas más, más genéricas, que presentan el teatro castellano de finales del siglo como algo muy desarrollado. Un ejemplo muy reciente entre tantos es el de Pérez Priego, quien ha tratado de Celestina y de las representaciones en la ciudad de Salamanca. "Por la noticias que tenemos, - afi ma el estudioso- en la Salamanca de finales del siglo xv hubo una gran proliferación de fiestas $y$, por supuesto, de espectáculos teatrales, de los que son muestra algunas obras de Juan del Encina y de Lucas Fernández» (2008: 78). No cabe duda de que en la ciudad universitaria hubo en aquel entonces un ambiente de espectáculos y representaciones de varia índole bastante importante al que contribuyeron, principalmente, los dos dramaturgos mencionados, es decir, Encina y Fernández. Sin embargo, si se compara la situación castellana con la de la península italiana recordada arriba o, simplemente, si se piensa en al abismo que hay entre las églogas de los dos escritores y Celestina, se ve bien cómo esta "gran proliferación de fiestas $y$, por supuesto, de espectáculos teatrales» se reduce a bien poca cosa y no ayuda en nada a explicar la génesis de la Tragicomedia de Calisto y Melibea, obra maestra española que está estrechamente relacionada con el drama clásico y humanístico. ${ }^{24}$

24.- La mayoría de los estudiosos aceptan y reconocen, hoy en día, la influencia de la comedia humanística en la génesis de Celestina (véase, entre las contribuciones más recientes, la de Canet Vallés 2011: 31-46). Sin embargo, aunque los puntos de contacto que se han 
Volviendo al tema principal de nuestro trabajo, ¿qué documentación tenemos hoy en día de representaciones escénicas o recitales de Plauto y Terencio en España a finales del siglo XV? La respuesta, desgraciadamente, es muy simple: ninguna, absolutamente ninguna.

De la segunda década del siglo XVI es la traducción del Amphitruo de Plauto por el médico Francisco López de Villabos, ${ }^{25}$ pero esta se hizo, como ha subrayado Quintero (1990: 238), no con el objetivo de una posible recitación sino de una lectura -aunque el médico demuestra en el Prohemio tener conciencia de la posibilidad de representación de la obra-. ${ }^{26}$ De alrededor de 1525 es la adaptación de la misma comedia plautina por Fernán Pérez de Oliva (Quintero 1990). En 1527 se recitó en Valencia el Eunuchus de Terencio (Alonso Asenjo 1998: 154); hay referencia a la puesta en escena de comedias clásicas siempre en el Estudi General de Valencia por los años 1532 y 1535 (id. 164, n. 55). De 1538 son los ya citados Estatutos de la Universidad de Salamanca, cuya redacción, de todos modos, se remonta por lo menos a 1529, cuando era rector del ateneo salmantino el ya citado Fernán Pérez de Oliva (Fuertes Herreros 1984). ${ }^{27}$ Aunque Valero García (1988: 359-84) haya argüido que las reglamentaciones de 1529 no fueron sino un primer esbozo de las que se iban a aprobar y publicar nueve años más tarde, sin embargo sus efectos pueden verse ya desde 1530 , año en que unos bachilleres de gramática que enseñaban en la universidad fueron multados porque no representaron «la tragedia o comedia

señalado a favor de esta relación sean consistentes, queda todavía sin solución la total falta de noticias en España de los dramas humanísticos que más se acercan (por personajes, recursos, ambiente, ideología, etc.) a nuestra Tragicomedia. Hemos tratado de este asunto específico en un trabajo que se publicará pronto y al que remitimos (Paolini, en prensa).

25.- Sobre este personaje véase Granjel (1979). Acerca de su traducción, véanse Baca (1969), Tremallo (1989), Quintero (1990), Garrido Camacho (1999) e Illades (1999).

26.- «La trasladación es fielmente hecha, sin añadir ni quitar, salvo el prólogo que el poeta hace en nombre de Mercurio, y sus argumentos, que esto era bueno para representar la comedia en público y hacer farsa della, porque los miradores entendiesen bien los pasos todos. Aquí no se pone aquello, porque sería cosa desabrida y sin gusto. Bastan los argumentos que yo pongo, porque dan mejor a entender la comedia y son más sabrosos para los leyentes» (apud Quintero 1990: 238; el subrayado es nuestro).

27.- En los Estatutos de 1529, el título xxviI, núms. 201-225, se ocupa de reglamentar los cursos de gramática menores, medianos y mayores. En los cursos de menores, después de haber acabado con los primeros tres libros de la Gramática de Antonio de Nebrija había que explicarse «el quarto libro del arte [de Nebrija]... y a la tarde de primera comedia del Terencio, dos partes de versos, y despues de leydos platiquen las partes por este, preguntando a cada discipulo e provando por declinaciones, preteritos e supinos» (Tít. XXVII, núm. 207; Fuertes Herreros 1984: 168); en cuanto a los cursos medianos, leemos que "cada un año representen dos comedias... y sean anbas de Terencio, o la una del Terencio e la otra de Plauto, esto hagan quinze dias antes de San Juan o quinze dias despues, y el que dellos no lo hiziere sea multado en seys ducados de su salario para el arca del estudio» (Tít. XxviI, núm. 217; Fuertes Herreros 1984: 171). Sobre la enseñanza de la gramática en la Universidad de Salamanca en el siglo XVI, véanse Álvarez Aranguren (1990) y Alejo Montes (1993-1994). 
como lo manda el Estatuto» (Framiñán de Miguel 2002: 1196). ${ }^{28}$ Y ya en la segunda mitad del siglo son abundantes las informaciones que tenemos acerca de representaciones y traducciones tanto de comedias y tragedias de autores clásicos como de dramas escritos por autores de la época (Gil Fernández 1984; Alonso Asenjo 1998).

Sin embargo, como ya se ha dicho, no hay ningún documento ni indicio que aluda a una posible representación de comedias de Plauto y Terencio en España a finales del siglo XV. Por tanto, hasta que no se encuentre una mínima referencia, una alusión o una prueba concreta - algo que, por varias razones, nos parece muy difícil-, es preciso considerar la ausencia de informaciones acerca de representaciones de comedias clásicas no como un hecho histórico al que hay que buscar precedentes de otros países o inferir reglas universitarias que se dieron tres décadas después, sino como problema sustancial para entender la génesis de Celestina.

28.- Estas son las informaciones que presenta la estudiosa en el apéndice documental al final de su estudio y en la página citada: "Al curso de gramática de mayores, qu[e] es del bachiller Busto... fue multado en seis ducados porque no representó la tragedia o comedia como lo manda el Estatuto"; "Al curso de gramática de mayores, qu[e] es del bachiller Romero... fue multado en seis ducados porque no representó comedia o tragedia conforme al Estatuto"; "Al curso de medianos de gramática, qu[e] es de Almofara... fue multado en seis ducados porque no representó tragedia o comedia» (el subrayado es nuestro). Aunque no se declare abiertamente, probablemente los dramas que se pedía representar eran las comedias de Plauto y Terencio y las tragedias de Séneca. 


\section{Bibliografía}

Alejo Montes, Javier, "Los colegios de gramática en la Universidad de Salamanca en el siglo XVI», Historia de la educación XII-XIII (1993-1994), pp. 309-26.

Alonso Asenjo, Julio, "Panorámica del teatro estudiantil del Renacimiento español», Spettacoli studenteschi nell'Europa Umanistica, eds. M. Chiabò y F. Doglio, Roma, Torre d'Orfeo Editrice, 1998, pp. 151-91.

Álvarez Aranguren, Lucio, "La reforma de los estudios de Gramática en el siglo XVI promovida por Fray Luis de León», Revista de Ciencias de la Educación 143 (1990), pp. 231-46.

AratA, Alda, Niccolò da Correggio nella vita letteraria e politica del tempo suo, Bologna, Zanichelli, 1934.

Ardizzoni, Anthos, ed. y trad., Angelo Poliziano, Epigrammi greci, Firenze, La Nuova Italia, 1951.

BACA, Albert R., "A Study and Comparison of the Amphitryon Theme in Francisco de Villalobos and Juan de Timoneda», Hispanófila 35 (1969), pp. 1-17.

Bausi, Francesco, «Note sul Prologo ai 'Menecmi' del Poliziano», Interpres XI (1991), pp. 357-64.

BELCARI, Feo, Le rappresentazioni di Feo Belcari ed altre di lui poesie, Firenze, Ignazio Moutier, 1833.

Bombieri, Giovanna, "Osservazioni sul Prologo ai Menecmi di Angelo Poliziano", Tradizione classica e letteratura umanistica. Per Alessandro Perosa, eds. R. Cardini, E. Garin, L. Cesarini Martinelli y G. Pascucci, Roma, Bulzoni, 1985, vol. II, pp. 489-506.

Bonilla y SAn Martín, Adolfo, "El Teatro escolar en el Renacimiento español y un fragmento inédito del toledano Juan Pérez», Homenaje a Menéndez Pidal. Miscelánea de Estudios Lingüísticos, Literarios e Históricos, Madrid, Librería y Casa Editorial Hernando, 1925, vol. III, pp. 143-55.

Canet Vallés, José Luis, ed., Comedia de Calisto y Melibea, Universitat de València, Publicacions de la Universitat de València, 2011.

Casas Homs, José María, ed., Johannes de Vallata, Poliodorus, comedia humanística desconocida, Madrid, CSIC, 1953.

Coppo, Anna Maria, "Spettacoli alla corte di Ercole I», Contributi dell'Istituto di Filologia Moderna-Serie Storia del Teatro, 1, Milano, Università Cattolica del Sacro Cuore, 1968, pp. 30-59.

Cruciani, Fabrizio, "Il teatro dei ciceroniani: Tommaso Fedra Inghirami», Forum Italicum XIV (1980), pp. 357-77.

—, Teatro nel Rinascimento. Roma 1450-1550, Roma, Bulzoni, 1983. 
Cruciani, Fabrizio, Clelia Falletti y Franco Ruffini, «La sperimentazione a Ferrara negli anni di Ercole I e Ludovico Ariosto", Teatro e Storia IX (1994), pp. 131-217.

Cruciani, Fabrizio y Diego Seragnoli, Il teatro italiano nel Rinascimento, Bologna, Il Mulino, 1987.

De AmICIS, Vincenzo, L'imitazione latina nella commedia italiana del XVI secolo, Firenze, Sansoni, 1897.

Del Lungo, Isidoro, «Di altre recitazioni di commedie latine in Firenze nel sec. XV», Archivio Storico Italiano s. III, t. XXIII (1876), pp. 170-5.

Di Camillo, Ottavio, "Consideraciones sobre La Celestina y las instituciones dramatúrgicas del humanismo en lengua vulgar», en "La Celestina» 1499-1999. Selected Papers from the International Congress in Commemoration of the Quincentennial Anniversary of "La Celestina" (New York, November 17-19, 1999), eds. Ottavio Di Camillo y John O'Neill, New York, The Hispanic Seminary of Medieval Studies, 2005, pp. 53-74.

DizIONARIO Biografico degli Italiani, Roma, Istituto della Enciclopedia Italiana, 1962-.

Doglio, Federico, "Il teatro in latino nel Cinquecento", Il teatro classico italiano nel' 500. Atti del Convegno, Roma, Accademia dei Lincei, 1971, pp. 163-96.

ENCICLOPEDIA dello spettacolo, Roma, Le Maschere, 1954-1962.

Esperabé ArteAga, Enrique, Historia pragmática e interna de la Universidad de Salamanca, Salamanca, 1914-1917, 2 vols.

Framiñán de Miguel, $M^{a}$ Jesús, «Actividad dramática en el Estudio salmantino del Renacimiento: Plauto y Terencio", Humanismo y pervivencia del mundo clásico III: Homenaje al profesor Antonio Fontán (Alcañiz, 8 a 13 de mayo de 2000), Alcañiz-Cádiz, Instituto de Estudios Humanísticos, Ediciones del Laberinto, 2002, vol. 3, pp. 1187-1200.

Fuertes Herreros, José Luis, ed., Estatutos de la Universidad de Salamanca, 1529. Mandato de Pérez de Oliva, Rector, Salamanca, Universidad de Salamanca, 1984.

García Soriano, Justo, Teatro universitario y humanístico de España, Toledo, Talleres tipográficos de R. Gómez, 1945

GaRRido CAMACHo, Patricia, El tema del reconocimiento en el teatro español del siglo XVI. La teoría de la anagnórisis, Madrid, Editorial Támesis, 1999.

Gil FernándeZ, Luis, «Terencio en España: del Medievo a la Ilustración», Estudios de humanismo y tradición clásica, Madrid, Editorial de la Universidad Complutense, 1984, pp. 95-125.

Gilman, Stephen, The Spain of Fernando de Rojas, Princeton, Princenton UP, 1972.

Granjel, Luis S., Vida y obra de López de Villalobos, Salamanca, Universidad, 1979.

Guarino, Raimondo, "Cherea, o le commedie nella città», Biblioteca Teatrale, n.s., 5-6 (1987), pp. 29-52. 
—, ed., Teatro e culture della rappresentazione. Lo spettacolo in Italia nel Quattrocento, Bologna, Il Mulino, 1988.

-, Teatro e mutamenti. Rinascimento e spettacolo a Venezia, Bologna, Il Mulino, 1995.

Illades Aguiar, Gustavo, "La Celestina» en el taller salmantino, Publicaciones Medievalia, 21, México, Universidad Nacional Autonoma de México, 1999.

Lattanzi Roselli, Rosetta, ed., Angelo Poliziano, La commedia antica e $l^{\prime}$ «Andria» di Terenzio, Firenze, Sansoni, 1973.

Legrand, Émile L. J., Bibliographie hellénique ou description raisonnée des ouvrages publiés en Grec aux XVe et XVI siècles, Paris, 1885.

Lida de Malkiel, María Rosa, La originalidad artística de "La Celestina", Buenos Aires, Eudeba, 1970.

Luzio, Alessandro y Rodolfo RenieR, "Delle relazioni di Isabella d'Este Gonzaga con Ludovico e Beatrice Sforza», Archivio storico lombardo, II s., XVII (1890), pp. 74-119; pp. 346-99; pp. 619-74.

Martelli, Mario, "Il prologo di Poliziano ai 'Menaechmi' di Plauto", Le tradizioni del testo. Studi di letteratura italiana offerti a Domenico de Robertis, eds. Franco Gavazzeni y Guglielmo Gorni, Milano-Napoli, Ricciardi, 1993, pp. 69-83.

Menéndez Pelayo, Marcelino, Orígenes de la novela, tomo III (Novelas dialogadas), Madrid, Casa Editorial Bailly \& Baillière, 1910.

Molinari, Cesare, Spettacoli fiorentini del Quattrocento, Venezia, Neri Pozza, 1961.

NeIIEndam, Klaus, "Le théâtre de la Renaissance à Rome», Analecta Romana Instituti Danici v (1969), pp. 103-97.

Orlando, V., «Le edizioni rinascimentali dei volgarizzamenti di Plauto e Terenzio", Aevum XVI (1940), pp. 573-81.

PADOAN, Giorgio, La commedia rinascimentale veneta (1433-1565), Vicenza, Neri Pozza, 1982.

-, L'avventura della commedia rinascimentale, Padova, Piccin, 1996.

Pagliaroli, Stefano, "Giano Lascaris e il Ginnasio greco", Studi medievali e umanistici 2 (2004), pp. 215-93.

PaOlini, Devid, "La comedia humanística, La Celestina y España», Actas del XVII Congreso de la Asociación Internacional de Hispanistas (Roma, julio de 2011), en prensa.

Pérez Priego, Miguel Ángel, "Celestina y algunas representaciones teatrales en la Salamanca de Rojas», Theatralia x (2008), pp. 77-88.

PesentI, Giovanni B., "Lettere inedite del Poliziano", Athenaeum 3 (1915), pp. 284-304.

Picón GarCía, Vicente, «Proyecto de investigación sobre teatro latino humanístico en España", Actas I Simposio sobre humanismo y pervivencia del mundo clásico (Alcañiz, 8 a 12 de mayo de 1990), Cádiz, 1993, pp. 821-30. 
PIERI, Marzia, La nascita del teatro moderno in Italia tra XV e XVI secolo, Torino, Bollati Boringhieri, 1989.

PINTOR, Fortunato, Le prime recitazioni di commedie latine in Firenze nel sec. XV, Miscellanea nuziale Ferrari-Toniolo, Perugia, 1906a.

-, Rappresentazioni romane di Seneca e Plauto nel Rinascimento, Miscellanea nuziale Provenzal-Bartelletti, Perugia, $1906 \mathrm{~b}$.

Quintero, María Cristina, "The Interaction of Text and Culture in Spanish Renaissance 'Translations' of Plautus' Amphytruo», Bulletin of Hispanic Studies LXVII (1990), pp. 235-52.

Robin, Diana, ed. y trad., Cassandra Fedele, Letters and Orations, Chicago, The U of Chicago P, 2000.

Rositi, F., "La commedia rinascimentale e le prime traduzioni di Plauto rappresentate a Ferrara", Contributi dell'Istituto di Filologia Moderna-Serie Storia del Teatro, 1, Milano, Università Cattolica del Sacro Cuore, 1968, pp. 1-29.

Rossi, Vittorio, Il Quattrocento, nona ristampa della prima edizione riveduta e corretta con supplemento bibliografico (1932-1971) a cura di Aldo Vallone, Milano, Casa Editrice Dr. Francesco Vallardi, 1973.

Ruffini, F., "Preliminari per un'analisi dei Menaechmi ferraresi del 1486», Schifanoia III (1987), pp. 125-35.

Sanesi, Ireneo, La commedia, Milano, Casa Editrice Dr. Francesco Vallardi, 1911.

STÄUBle, Antonio, La commedia umanistica del Quattrocento, Firenze, Istituto Nazionale di Studi sul Rinascimento, 1968.

Stefani, Luigina, «Sui volgarizzamenti plautini a Ferrara e a Mantova nel tardo Quattrocento», Paragone. Letteratura 358 (1979), pp. 61-75.

Tissoni Benvenuti, Antonia y Maria Pia Mussini Sacchi, Teatro del Quattrocento. Le corti padane, Torino, UTET, 1983.

Tremallo, Beth S., "El Anfitrión de Francisco López Villalobos», Anuario de Letras 27 (1989), pp. 313-28.

TreXler, Richard C., "Florentine Theatre, 1280-1500. A Checklist of Performances and Institutions», Forum Italicum XIV (1980), pp. 454-75.

Uberti, Maria Luisa, I "Menechini» di Plauto. Volgarizzamenti rinascimentali, Ravenna, Longo Editore, 1985.

Valero García, Pilar, La Universidad de Salamanca en la época de Carlos V, Salamanca, Universidad, 1988.

Ventrone, Paola, «Riflessioni teoriche sul teatro nella Firenze dei primi Medici», Interpres XII (1992), pp. 150-96.

-, Gli araldi della commedia. Teatro a Firenze nel Rinascimento, Pisa, Pacini Editore, 1993.

-, Lo spettacolo religioso a Firenze nel Quattrocento, Milano, ISU-Cattolica, 2008, 2 vols.

Villoresi, Marco, Da Guarino a Boiardo. La cultura teatrale a Ferrara nel Quattrocento, Roma, Bulzoni, 1994. 
ZABUGHin, Vladimir, Giulio Pomponio Leto, Roma-Grottaferrata, 1909-1912. 2 vols.

Zorzi, Ludovico, Il teatro e la città. Saggi sulla scena italiana, Torino, Einaudi, 1977.

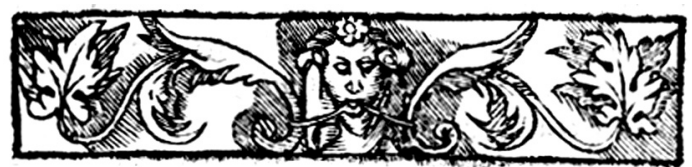




\section{PAOLINI, Devid, «Sobre un tópico equivocado (las representaciones de las comedias de Plauto y Terencio en España a finales del siglo xv) y Celestina», Celestinesca, 35 (2011), pp. 67-84.}

\section{RESUMEN}

Antes de aceptar la pertenencia de Celestina al ámbito dramático y la comedia clásica romana como uno de sus modelos, es necesario aclarar de manera satisfactoria un problema determinante: la total ausencia, en Castilla, de documentación acerca de representaciones de comedias de Plauto y Terencio a finales del siglo XV. Aunque algunos estudiosos hayan afirmado que en esta época solían representarse en España las obras de estos dramaturgos latinos, desgraciadamente no han aducido evidencia o prueba ninguna en apoyo de sus aseveraciones, por lo que nunca se han podido confirmar históricamente tales prácticas teatrales. Esta creencia infundada ha surgido, probablemente, de la voluntad de querer homologar la tradición teatral de la península italiana del último cuarto del siglo XV a España. Sin embargo, esta evidente incongruencia persiste y no ayuda en nada a explicar la génesis de Celestina.

Palabras ClaVe: Celestina, Plauto, Terencio, drama, representación, Italia, España.

\section{ABSTRACT}

Before including Celestina in the dramatic genre or accepting the roman comedy as one of its models, we need to find a satisfactory answer to a major problem: the total absence, in Castile, of documentation relating to any performance of Plautus and Terence's comedies at the end of the 15th century. Although some scholars have affirmed that in the Spain of the time the works of both Latin playwrights were performed, they have not offered a single documentary evidence that could prove it. This unfounded belief was probably due to the uncritical attempt of establishing a facile homology between the dramatic tradition of the Italian peninsula, where such representations were common, with the Spanish situation, where they appear to be lacking. Nevertheless, such an obvious incongruity continues to be repeated and it does not help to explain the genesis of Celestina.

KEY WORDS: Celestina, Plauto, Terence, drama, performance, Italy, Spain 